\title{
Stereotactic radiosurgery for hypersecreting pituitary tumors: part of a multimodality approach
}

\author{
John A. Jane, JR., M.D., Mary Lee Vance, M.D., C. J. Woodburn, B.S., \\ AND EDWARD R. LAWS, JR., M.D. \\ Departments of Internal Medicine and Neurological Surgery, University of Virginia, Health Sciences \\ Center, Charlottesville, Virginia
}

\begin{abstract}
Object. Surgical and medical therapies successfully achieve biochemical remission in the majority of patients with secretory pituitary adenomas. Nevertheless, continued hypersecretion after first-line therapy occurs and requires adjunctive therapy to prevent morbidity and premature mortality. For patients in whom medical and surgical therapy have failed, gamma knife surgery (GKS) is performed with the goal of controlling tumor growth and excess growth hormone $(\mathrm{GH})$ production. The authors report their experience with GKS in patients in whom surgical and medical therapies failed.

Methods. The neuroendocrine service at the University of Virginia has treated 220 patients with secretory adenomas. The authors evaluated the biochemical results in patients with acromegaly followed for greater than 18 months (64 patients) as well as those with Cushing disease (45 patients), Nelson syndrome (14 patients with adequate follow up [27 overall]), and prolactinomas (19 patients) followed for at least 12 months posttreatment. Biochemical remission occurred in $36 \%$ of patients with GH-secreting adenomas, $73 \%$ of those with Cushing disease, $14 \%$ of those with Nelson syndrome, and $11 \%$ of those harboring prolactinomas. Recurrence after biochemical remission was documented in four patients with Cushing disease. New hormonal deficits have occurred in $28 \%$ of patients with acromegaly, $31 \%$ with Cushing disease, $36 \%$ with Nelson syndrome, and $21 \%$ with prolactinomas. Minor visual deterioration developed in one patient with Cushing disease.

Conclusions. Gamma knife surgery offers an important treatment modality in patients with secretory adenomas refractory to surgical and medical interventions.
\end{abstract}

\section{KEY WORDS • pituitary adenoma • stereotactic radiosurgery}

The current treatment paradigms for functioning pituitary adenomas require a multidisciplinary approach. Surgeons, endocrinologists, radiation therapists and radiosurgeons each have an ongoing role in the individualized management of these often-complex tumors. Each therapeutic modality has a complementary role in the comprehensive treatment of patients with pituitary adenomas.

In the overwhelming majority of patients, surgical or medical therapy is the most appropriate first-line treatment. Whereas transsphenoidal surgery remains the firstline therapy for acromegaly and Cushing disease, the vast majority of prolactinomas are best treated initially with medical therapies. Patients with acromegaly and Cushing disease in whom hypersecretion persists postoperatively undergo medical therapy. If this fails, radiotherapy is an alternative. In addition, although pharmacotherapy can control excessive hormone levels in patients with acromegaly and Cushing disease, it does not currently effect a "cure." Radiotherapy may offer this cure.

Abbreviations used in this paper: $\mathrm{ACTH}=$ adrenocorticotropic hormone; GH = growth hormone; GKS = gamma knife surgery; IGF-I = insulin-like growth factor-I; PRL = prolactin; UFC = urinary free cortisol.
Patients with prolactinomas in whom there is no response to dopamine agonist therapy often require a combination of surgery and radiotherapy. Surgery may offer cure in patients with small noninvasive prolactinomas; however, those who harbor large tumors or tumors invading the cavernous sinus will require radiotherapy. Transsphenoidal surgery is often performed prior to radiotherapy to reduce tumor burden and to provide a safe margin between the tumor and the optic chiasm.

In this article we examine our experience with adjunctive GKS after unsuccessful surgical and medical interventions.

\section{CLINICAL MATERIAL AND METHODS}

\section{Pretreatment Management}

Patients undergo a full assessment of baseline pituitary function prior to GKS. Because there are data to suggest that the efficacy of radiotherapy is diminished in patients with acromegaly wjp are receiving somatostatin analogs at the time of radiation therapy, we now delay medical treatment until at least 6 weeks after radiosurgery. ${ }^{25} \mathrm{Sim}$ ilar data regarding responsiveness to radiosurgery in patients with prolactinomas have led us also to delay dopa- 
mine agonist therapy for 6 weeks. ${ }^{27}$ Medical therapy is not withheld prior to radiosurgery in patients with Cushing disease because of the significant deleterious effects of excessive adrenal cortisol production and because medical therapy (ketoconazole) has no direct effect on the pituitary gland.

\section{Endocrinological Follow-Up Examination}

Because radiotherapy is known to produce new endocrinological deficits, patients are evaluated every 6 months after GKS for the development of secondary hypothyroidism, hypogonadism, adrenal insufficiency, and GH deficiency. By obtaining a complete clinical history we screen for these hormonal deficiencies. Clinically, hypothyroidism is characterized by diminished physical and mental function. Symptomatically, fatigue, weight gain, constipation, cold intolerance, decreased alertness, headache, and depression may be evident. Male hypogonadism manifests with diminished libido or erectile dysfunction. In women, amenorrhea, diminished libido, and hot flashes may occur. Patients with adrenal insufficiency often report weakness, fatigue, anorexia or weight loss, gastrointestinal symptoms, myalgia, arthralgia, and postural dizziness. Growth hormone deficiency manifests with diminished tolerance to exercise, increased central adiposity, a diminished mood or sense of well-being, and increased anxiety.

Guided by the clinical history, hormonal studies should be performed. These studies should include evaluation of serum thyroxine, testosterone, estradiol, and morning cortisol levels. Growth hormone deficiency may be screened using IGF-I levels, but a stimulation test, such as insulininduced hypoglycemia, is necessary to document the need for $\mathrm{GH}$ replacement therapy.

The biochemical efficacy of radiosurgery is also evaluated at these 6-month intervals. Medical therapy is discontinued 4 to 6 weeks prior to evaluation. In cases of acromegaly a normal age- and sex-adjusted IGF-I level defines remission. Patients with Cushing disease are evaluated using the 24-hour UFC determination. Patient with Nelson syndrome are assessed with a serum ACTH level. Remission in patients with prolactinomas is determined by simply using a single random serum PRL measurement. Neuroimaging evaluation is performed annually by using magnetic resonance imaging.

\section{Patient Population}

Under the guidance and direction of Ladislau Steiner, our multidisciplinary neuroendocrine service at the University of Virginia performed GKS in 354 patients with pituitary disorders between June 1989 and May 2002. The typical GKS marginal dose was 15 Gy. Of the 354 patients, 220 harbored secretory adenomas, including 91 patients with acromegaly, 73 with Cushing disease, 27 with Nelson syndrome, and 29 with prolactinomas. Only those patients with $\mathrm{GH}$-secreting tumors followed for more than 18 months were included. A follow-up period of greater than 12 months was considered adequate for patients with Cushing disease, Nelson syndrome, and prolactinomas. Thus, the population included 64 patients with acromegaly, 45 with Cushing disease, 14 with Nelson syndrome, and 19 with prolactinomas.

\section{RESULTS}

\section{Patients With Acromegaly}

Of the 64 patients with adequate follow up, age- and sex-adjusted IGF-I levels normalized in 36\% (23 patients) (Table 1). The mean time to normalization was 28 months (range 5-98 months). One patient, in whom disease remission did not occur, underwent a repeated GKS. There have been no recurrences in this population after biochemical remission. New hormonal deficiencies were noted in $28 \%$ (18 patients). One patient in the group died of uncertain causes during the follow-up period.

\section{Cushing Disease and Nelson Syndrome}

Of the 45 patients with Cushing disease, a normalized 24-hour UFC was achieved in $73 \%$ (33 patients). The mean time to remission was 16 months (range 2-62 months). Recurrent disease occurred in two patients who underwent repeated GKS. New hormonal deficits were noted in $31 \%$ (14 patients). One patient experienced minor visual deterioration (partial quadrantanopsia). Three patients died during the follow-up period, one of progressive Cushing disease, one of myocardial infarction, and one of sepsis.

In two of the 14 patients with Nelson syndrome a normalized ACTH level was documented. New hormonal deficits developed in 36\% (five patients). Three patients died, two of progressive disease and one of unknown causes.

\section{Patients With Prolactinoma}

Of the 19 patients with prolactinomas, normalization of serum PRL levels was documented in $11 \%$ (two patients). The mean time to remission was 20.5 months (range 18-23 months). No disease recurrence developed after remission. New hormonal deficiency was noted in $21 \%$ (four patients). Three patients died during the follow-up period, two of disease progression and one of myocardial infarction.

\section{DISCUSSION}

\section{Role of GKS in Multimodal Therapy}

The efficacy of GKS for secretory pituitary adenomas must be understood in the context of an overall multimodal treatment plan. Patients selected for GKS are those in whom first- and second-line therapies have failed and who remain at significant risk for morbidity and premature mortality associated with hormonal hypersecretion. It

TABLE 1

Results of GKS for hypersecreting adenomas

\begin{tabular}{lccr}
\hline \multicolumn{1}{c}{ Diagnosis } & Remission (\%) & $\begin{array}{c}\text { Mean No. of } \\
\text { Mos. to Remis- } \\
\text { sion (Range) }\end{array}$ & $\begin{array}{c}\text { New } \\
\text { Hormonal } \\
\text { Deficits (\%) }\end{array}$ \\
\hline acromegaly & $23(36)$ of 64 & $28(5-98)$ & $18(28)$ of 64 \\
Cushing disease & $33(73)$ of 45 & $16(2-62)$ & $14(31)$ of 45 \\
nelson syndrome & $2(14)$ of 14 & $11.5(3-20)$ & $5(36)$ of 14 \\
prolactinoma & $2(11)$ of 19 & $20.5(18-23)$ & $4(21)$ of 19 \\
\hline
\end{tabular}


is within the context of these difficult circumstances that the role of GKS should be appreciated.

Acromegaly. Transsphenoidal surgery, when performed as primary therapy, can achieve biochemical remission in $87 \%$ of patients with microadenomas and $50 \%$ of those with macroadenomas. ${ }^{28,30}$ In patients in whom surgery achieves biochemical remission, recurrence at 10 years is nearly $10 \% .{ }^{29}$ Reoperation is often a viable option, and in our experience, $48 \%$ of patients with acromegaly achieved remission after repeated operation. ${ }^{16,23,29}$ Nevertheless, the likely need for adjuvant medical therapy or radiotherapy is recognized for cases involving large tumors and tumors with cavernous sinus invasion.

Although dopamine agonists provide symptomatic relief in the majority of patients, they are relatively ineffective in normalizing GH or IGF-I levels. ${ }^{1,12-14,22,46}$ Somatostatin analogs provide a more effective treatment option and can normalize IGF-I levels in 50 to $60 \%$ of patients. ${ }^{3,8,9,11,24,36}$ The more recently introduced GH receptor antagonists appear to have encouraging prospects. In series of patients with disease refractory to surgery and maximum conventional medical therapy, some investigators have shown that up to $100 \%$ of patients experience hormonal normalization and a halt in tumor growth after treatment with GH receptor agonists. ${ }^{18,20}$ Despite these encouraging results, the likelihood is that a certain percentage of patients with otherwise refractory GH-secreting adenomas will continue to need the radiosurgical option. That an additional $36 \%$ of patients may experience hormonal normalization makes GKS a viable option.

Cushing Disease and Nelson Syndrome. In our experience, transsphenoidal adenomectomy achieves biochemical remission in $90 \%$ of patients with microadenomas and 46 to $60 \%$ of patients harboring macroadenomas. ${ }^{28,40}$ Of the patients experiencing biochemical remission, recurrence is demonstrated in approximately $12 \%$. Pharmacotherapy involving adrenolytic therapy (ketoconazole, mitotane) can significantly reduce UFC levels but normalization is demonstrated in fewer than half of the patients. ${ }^{10,21,43}$ Patients with refractory Cushing disease appear to benefit significantly from GKS. In our series, biochemical remission occurred in nearly $75 \%$ of patients and did so in a mean of 16 months.

Prolactinomas. Medical therapy remains the first-line treatment of PRL-secreting adenomas.,34 The dopamine agonists (bromocriptine, pergolide, cabergoline) normalize prolactin levels in 67 to $89 \%$ of patients. ${ }^{2,31,33,47}$ Tumors recede by at least $50 \%$ in nearly two thirds of patients, and visual field deficits improve in $90 \% .^{33}$ Tumor reduction occurs within 6 weeks in the majority of patients. ${ }^{33}$

Patients in whom pharmacotherapy fails may be categorized into two groups: those who are intolerant of and those who are resistant to medical therapy. A small percentage of patients are unable to tolerate the mostly gastrointestinal side effects of the dopamine agonists. Resistance is characterized by either failure of prolactin levels to normalize or failure of the tumor to decrease in size. In these circumstances, surgery is indicated.

Depending on the preoperative PRL level, surgery can normalize this function in 50 to $88 \%$ of patients harboring microadenomas. ${ }^{32,38}$ In patients with microprolactinomas, the lesion recurs in 17 to $50 \% .{ }^{32,41}$ In patients with macro- prolactinomas surgical remission is less successful, occurring in 28 to $53 \%$ of patients..$^{32,38}$ The recurrence rate is also greater (as high as $80 \%$ ). ${ }^{32,41}$ Based on this series, it is our finding that in difficult cases GKS can induce a remission in an additional $11 \%$ of patients off medication.

\section{Comparison of GKS and Conventional Radiotherapy}

An exact comparison of radiosurgery and conventional radiotherapy is not possible in this study. Attempts to compare our results with those published in past conventional radiotherapy-based studies are difficult because the latter did not use modern definitions of remission. In addition, follow-up data have been collected over a longer period for conventional radiotherapy, allowing a more accurate determination of its related long-term efficacy and complications. Nevertheless, an attempt will be made to draw certain reasonable comparisons.

Acromegaly. Conventional fractionated radiotherapy has been shown to normalize IGF-I levels in 16 to $60 \%$ of patients after 10 years. ${ }^{4,15,37}$ Remission increases with time after radiotherapy; whereas normalized IGF-I levels occurred in $27 \%$ cases before 6 years, Powell and colleagues ${ }^{37}$ reported that remission increased to $69.2 \%$ after an interval of greater than 6 years. Similarly Barrande, et al., ${ }^{4}$ reported that IGF-I levels were normalized in $25 \%$ of the patients by 5 years and $60 \%$ by 10 years. Biermasz and colleagues $^{5,6}$ reported better results noting that normalized IGF-I levels occurred in $18(60 \%)$ of 30 patients at 5 years, $23(74 \%)$ of 31 at 10 years, and $16(84 \%)$ of 19 at 15 years. Comparing these results with our series is, of course, imperfect. In the $36 \%$ of our patients in whom biochemical remission was achieved, however, remission occurred in a mean of 28 months. It does appear that the effect of GKS manifests earlier than conventional fractionated radiotherapy. The results of other studies seem to support this conclusion. ${ }^{26,35}$ Landolt and colleagues ${ }^{26}$ reported that IGF-I and GH levels normalized with a mean of 1.4 years after stereotactic radiosurgery compared with a mean of 7.1 years after conventional fractionated radiotherapy.

Cushing Disease. We found that in patients treated with GKS a biochemical remission rate of $73 \%$ was documented at a mean of 16 months. Other authors have also reported this rapid remission. ${ }^{17,35,42}$ Conventional fractionated radiotherapy also appears effective after failed transsphenoidal surgery. Savage and colleagues ${ }^{39}$ reported biochemical remission in $82 \%$ after a median period of 8 years. Conventional radiotherapy is also reported to induce remission (normal UFC and suppression after high-dose dexamethasone) in $83 \%$ of patients in a mean follow-up period of 42 months. Eighty-eight percent of these remissions were reported to have occurred during the first 2 years after treatment. ${ }^{19}$ Others, however, have reported a lower remission rate as well as a significant incidence of recurrence after normalization in patients treated with conventional radiotherapy. ${ }^{7,45}$

Prolactinomas. Conventional fractionated radiotherapy has been reported to achieve normalized PRL levels in $50 \%$ of patients at a mean of 8.5 years. ${ }^{44}$ Although the remission rate was lower in our present series (11\%), this normalization occurred at a mean of 20.5 months following radiosurgery. 
Late Endocrinopathy. Both GKS and conventional radiotherapy are associated with long-term injury to the normal pituitary gland. In our series, new endocrine deficits were evident in 21 to $36 \%$ of patients. The literature pertaining to conventional radiotherapy indicates that at 10 years conventional irradiation induces thyroid deficiency in 35 to $78 \%$, glucocorticoid deficiency in 22 to $82 \%$, and gonadal dysfunction in 22 to $80 \%$ of patients. ${ }^{4,45}$ At least partial hypopituitarism was reported in $50 \%$ at 10 years and $75 \%$ at 15 years., ${ }^{5,6}$ More extended followup intervals in the radiosurgical population is certainly necessary because endocrinopathies should increase with time. The higher-dose radiation provided by the gamma knife, which appears to provide more rapid biochemical remission, may also cause a higher incidence of endocrinopathy.

\section{CONCLUSIONS}

Gamma knife radiosurgery has a significant role in the multimodal treatment of secretory pituitary adenomas. The gamma knife is most effective in the setting of unsuccessful transsphenoidal surgery for Cushing disease. Nevertheless, it does provide a biochemical remission in patients without medication in nearly $30 \%$ of the cases involving with acromegaly and $11 \%$ involving prolactinomas. Gamma knife radiosurgery appears to effect remission more rapidly than conventional radiotherapy. A longer follow-up period is necessary, however, to determine whether the remissions are durable.

\section{References}

1. Abs R, Verhelst J, Maiter D, et al: Cabergoline in the treatment of acromegaly: a study in 64 patients. J Clin Endocrinol Metab 83:374-378, 1998

2. Acquati S, Pizzocaro A, Tomei G, et al: A comparative evaluation of effectiveness of medical and surgical therapy in patients with macroprolactinoma. J Neurosurg Sci 45:65-69, 2001

3. Baldelli R, Colao A, Razzore P, et al: Two-year follow-up of acromegalic patients treated with slow release lanreotide (30 mg). J Clin Endocrinol Metab 85:4099-4103, 2000

4. Barrande G, Pittino-Lungo M, Coste J, et al: Hormonal and metabolic effects of radiotherapy in acromegaly: long-term results in 128 patients followed in a single center. J Clin Endocrinol Metab 85:3779-3785, 2000

5. Biermasz NR, Dulken HV, Roelfsema F: Postoperative radiotherapy in acromegaly is effective in reducing GH concentration to safe levels. Clin Endocrinol 53:321-327, 2000

6. Biermasz NR, van Dulken H, Roelfsema F: Long-term followup results of postoperative radiotherapy in 36 patients with acromegaly. J Clin Endocrinol Metab 85:2476-2482, 2000

7. Blevins LS, Christy JH, Khajavi M, et al: Outcomes of therapy for Cushing's disease due to adrenocorticotropin-secreting pituitary macroadenomas. J Clin Endocrinol Metab 83:63-67, 1998

8. Cannavo S, Squadrito S, Curto L, et al: Results of a two-year treatment with slow release lanreotide in acromegaly. Horm Metab Res 32:224-229, 2000

9. Caron P, Morange-Ramos I, Cogne M, et al: Three year followup of acromegalic patients treated with intramuscular slowrelease lanreotide. J Clin Endocrinol Metab 82:18-22, 1997

10. Chou SC, Lin JD: Long-term effects of ketoconazole in the treatment of residual or recurrent Cushing's disease. Endocr J 47:401-406, 2000

11. Colao A, Ferone D, Marzullo P, et al: Long-term effects of de- pot long-acting somatostatin analog octreotide on hormone levels and tumor mass in acromegaly. J Clin Endocrinol Metab 86:2779-2786, 2001

12. Colao A, Lombardi G: Growth-hormone and prolactin excess. Lancet 352:1455-1461, 1998

13. Colao A, Marzullo P, Ferone D, et al: Effectiveness and tolerability of slow release lanreotide treatment in active acromegaly. J Endocrinol Invest 22:40-47, 1999

14. Cozzi R, Attanasio R, Barausse M, et al: Cabergoline in acromegaly: a renewed role for dopamine agonist treatment? Eur J Endocrinol 139:516-521, 1998

15. Cozzi R, Barausse M, Asnaghi D, et al: Failure of radiotherapy in acromegaly. Eur J Endocrinol 145:717-726, 2001

16. Davis DH, Laws ER Jr, Ilstrup DM, et al: Results of surgical treatment for growth hormone-secreting pituitary adenomas. J Neurosurg 79:70-75, 1993

17. Degerblad M, Rahn T, Bergstrand G, et al: Long-term results of stereotactic radiosurgery to the pituitary gland in Cushing's disease. Acta Endocrinol 112:310-314, 1986

18. Drake WM, Parkinson C, Akker SA, et al: Successful treatment of resistant acromegaly with a growth hormone receptor antagonist. Eur J Endocrinol 145:451-456, 2001

19. Estrada J, Boronat M, Mielgo M, et al: The long-term outcome of pituitary irradiation after unsuccessful transsphenoidal surgery in Cushing's disease. N Engl J Med 336:172-177, 1997

20. Herman-Bonert VS, Zib K, Scarlett JA, et al: Growth hormone receptor antagonist therapy in acromegalic patients resistant to somatostatin analogs. J Clin Endocrinol Metab 85: 2958-2961, 2000

21. Invitti C, Giraldi FP, de Martin M, et al: Diagnosis and management of Cushing's syndrome: results of an Italian multicentre study. Study Group of the Italian Society of Endocrinology on the Pathophysiology of the Hypothalamic-Pituitary-Adrenal Axis. J Clin Endocrinol Metab 84:440-448, 1999

22. Jaffe CA, Barkan AL: Treatment of acromegaly with dopamine agonists. Endocrinol Metab Clin North Am 21:713-735, 1992

23. Kreutzer J, Vance ML, Lopes MB, et al: Surgical management of GH-secreting pituitary adenomas: an outcome study using modern remission criteria. J Clin Endocrinol Metab 86: 4072-4077, 2001

24. Lamberts SW, van der Lely AJ, de Herder WW, et al: Octreotide. N Engl J Med 334:246-254, 1996

25. Landolt AM, Haller D, Lomax N, et al: Octreotide may act as a radioprotective agent in acromegaly. J Clin Endocrinol Metab 85:1287-1289, 2000

26. Landolt AM, Haller D, Lomax N, et al: Stereotactic radiosurgery for recurrent surgically treated acromegaly: comparison with fractionated radiotherapy. J Neurosurg 88:1002-1008, 1998

27. Landolt AM, Lomax N: Gamma knife radiosurgery for prolactinomas. J Neurosurg (Suppl 3) 93:14-18, 2000

28. Laws ER, Jane JA Jr: Pituitary tumors-long-term outcomes and expectations. Clin Neurosurg 48:306-319, 2001

29. Laws ER Jr: Acromegaly and gigantism, in Wilkins RH, Rengachary SS (eds): Neurosurgery, ed 2. New York: McGrawHill, 1996, Vol 1, pp 1317-1320

30. Laws ER, Vance ML, Thapar K: Pituitary surgery for the management of acromegaly. Horm Res 53:71-75, 2000

31. Liuzzi A, Dallabonzana D, Oppizzi G, et al: Low doses of dopamine agonists in the long-term treatment of macroprolactinomas. N Engl J Med 313:656-659, 1985

32. Molitch ME: Pathologic hyperprolactinemia. Endocrinol Metab Clin North Am 21:877-901, 1992

33. Molitch ME, Elton RL, Blackwell RE, et al: Bromocriptine as primary therapy for prolactin-secreting macroadenomas: results of a prospective multicenter study. J Clin Endocrinol Metab 60:698-705, 1985 
34. Molitch ME, Thorner MO, Wilson C: Management of prolactinomas. J Clin Endocrinol Metab 82:996-1000, 1997

35. Morange-Ramos I, Regis J, Dufour H, et al: Gamma-knife surgery for secreting pituitary adenomas. Acta Neurochir 140: 437-443, 1998

36. Newman CB, Melmed S, George A, et al: Octreotide as primary therapy for acromegaly. J Clin Endocrinol Metab 83: 3034-3040, 1998

37. Powell JS, Wardlaw SL, Post KD, et al: Outcome of radiotherapy for acromegaly using normalization of insulin-like growth factor I to define cure. J Clin Endocrinol Metab 85: 2068-2071, 2000

38. Randall RV, Laws ER Jr, Abboud CF, et al: Transsphenoidal microsurgical treatment of prolactin-producing pituitary adenomas. Results in 100 patients. Mayo Clin Proc 58:108-121, 1983

39. Savage MO, Lienhardt A, Lebrethon MC, et al: Cushing's disease in childhood: presentation, investigation, treatment and long-term outcome. Horm Res (Suppl 1) 55:24-30, 2001

40. Semple PL, Vance ML, Findling J, et al: Transsphenoidal surgery for Cushing's disease: outcome in patients with a normal magnetic resonance imaging scan. Neurosurgery 46: 553-559, 2000

41. Serri O, Rasio E, Beauregard H, et al: Recurrence of hyperprolactinemia after selective transsphenoidal adenomectomy in women with prolactinoma. N Engl J Med 309:280-283, 1983
42. Shin M, Kurita H, Sasaki T, et al: Stereotactic radiosurgery for pituitary adenoma invading the cavernous sinus. J Neurosurg (Suppl 3) 93:2-5, 2000

43. Sonino N, Boscaro M: Medical therapy for Cushing's disease. Endocrinol Metab Clin North Am 28:211-222, 1999

44. Tsagarakis S, Grossman A, Plowman PN, et al: Megavoltage pituitary irradiation in the management of prolactinomas: longterm follow-up. Clin Endocrinol 34:399-406, 1991

45. Tsang RW, Brierley JD, Panzarella T, et al: Role of radiation therapy in clinical hormonally-active pituitary adenomas. Radiother Oncol 41:45-53, 1996

46. Wass JA, Thorner MO, Morris DV, et al: Long-term treatment of acromegaly with bromocriptine. Br Med J 1:875-878, 1977

47. Webster J, Piscitelli G, Polli A, et al: A comparison of cabergoline and bromocriptine in the treatment of hyperprolactinemic amenorrhea. Cabergoline Comparative Study Group. N Engl J Med 331:904-909, 1994

Manuscript received March 14, 2003.

Accepted in final form April 14, 2003.

Address reprint requests to: Edward R. Laws, Jr., M.D., Department of Neurological Surgery, University of Virginia Health Sciences Center, Box 212, Charlottesville, Virginia 22908. email: el5g@virginia.edu. 